\title{
WHICH ELEMENTS ARE EXCITED IN ELECTRICAL STIMULATION OF MAMMALIAN CENTRAL NERVOUS SYSTEM: A REVIEW
}

JAMES B. RANCK, Jr.*

Department of Physiology, University of Michigan, Ann Arbor, Mich. 48104 (U.S.A.)

(Accepted May 23rd, 1975)

SUMMARY

(1) There are data on the amount of current necessary to stimulate a myelinated fiber or cell body and/or its axon a given distance away from a monopolar electrode over the entire range of practical interest for intracranial stimulation. Data do not exist for other electrode configurations.

(2) Currents from a monopolar cathode of more than 8 times threshold may block action potentials in axons. Therefore, only axons lying in a shell around the electrode are stimulated. Elements very close to the electrode may not be stimulated. Close to an electrode small diameter axons may be stimulated and larger ones may not be.

(3) Most, and perhaps all, CNS myelinated fibers have chronaxies of 50-100 $\mu \mathrm{sec}$. When gray matter is stimulated, the chronaxie is often $200-700 \mu \mathrm{sec}$. It is not clear what is being stimulated in this case. Current-duration relations should be determined for many more responses.

(4) There are no current-distance or current-duration data for central finely myelinated or unmyelinated fibers.

(5) It takes less cathodal current than anodal to stimulate a myelinated fiber passing by a monopolar electrode. When a monopolar electrode is near a cell body, on the opposite side from the axon, often the lowest threshold is anodal, but sometimes cathodal. Stimulation of a neuron near its cell body is not well understood, but in many cases the axon is probably stimulated.

(6) Orientation of cell body and axons with respect to current flow is important.

* Current address: Department of Physiology, Downstate Medical Center, State University of New York, Brooklyn, N.Y. 11203, U.S.A. 
For an axon it is the component of the voltage gradient parallel to the fiber that is important.

(7) The pia has a significant resistance and capacitance. Gray matter, white matter, and cerebrospinal fluid have different resistivities, which affect patterns of current flow.

(8) More is known about stimulation of mammalian CNS than most workers are aware of. Much of what is unknown seems solvable with current methods.

INTRODUCTION

Despite the extensive use of electrical stimulation of the central nervous system (CNS), both clinically and experimentally, there has been little concern with what cells or parts of cells are stimulated. The data available on this issue are rarely cited in reports involving electrical stimulation, although, as this review will show, there is much information on the subject of practical use. This subject has never been reviewed before.

The phrase 'electrical stimulation of the lateral hypothalamus' is a shortened version of the statement that 'there was a stimulating electrode in the lateral hypothalamus which affected an unknown number and unknown kinds of cells at unknown locations in the vicinity of the electrode'. The lateral hypothalamus is an area of brain and is not electrically excitable - only cells are. The abbreviated phrase suggests assumptions about the homogeneity of cells that are incorrect. Furthermore, as will be shown, some cells may be stimulated at a distance from an electrode, whereas similar cells closer to an electrode may not be stimulated.

To make accurate inferences about anatomical structures or physiological mechanisms involved in electrical stimulation, one must know which elements were stimulated. Attempts have been made to determine which elements were involved by Szabo and Milner ${ }^{67-69}$, Wetzel ${ }^{73}$, and in 'refractory period' experiments ${ }^{18,66}$ in lateral hypothalamus. However, none of these experiments was as inclusive as is possible with the use of existing methods and knowledge.

Many experimenters who electrically stimulate brain may not be interested in which cells are involved, but may be interested only in the behavioral consequences of the stimulation. However, these experimenters should perform and report their experiments in ways that would allow an interpretation at a cellular level by other experimenters.

Some kinds of stimuli are relatively selective for certain kinds of cellular elements. More selective stimulation may yield more selective consequences of stimulation.

Instruments, the results of stimulation except on the first element affected, the physical theory of stimulation, effects of varying frequency of pulses, duration of pulse trains, 'refractory period' experiments, and monophasic versus biphasic stimuli will not be discussed. This review is intended to be useful in planning and interpreting electrical stimulation of mammalian CNS. Since many of the workers stimulating 
brain (especially in clinical and behavioral contexts) are not trained in biophysics, this review will be developed from an empirical rather than physical perspective.

This review should also be of interest from a biophysical point of view. The study of extracellular stimulation is a way for studying electrophysiological properties of neurons. This approach has been rarely used. There is a mathematical literature on extracellular stimulation which is often useful, but which will only be touched on here for the sake of simplicity. By pointing out some of the gaps in our knowledge, I hope to motivate others to do some of the relevant experiments and theory. I think it is a subject which we can come close to solving with currently available methods.

Since this subject has never been reviewed before, and, as will be seen, the relevant facts are drawn from all parts of the neurophysiological, behavioral, and clinical literature, I am sure many reports of significant observations have been missed. I would appreciate hearing about these observations from readers.

\section{THE DATA}

\section{(A) Current-distance relations}

The task of trying to determine how much current is necessary to fire a given element a given distance from an electrode is more difficult than it appears. There are 4 reasons why one cannot simply record from an element with one electrode, place another stimulating electrode at a known position nearby, and determine the amount of current necessary to stimulate: (1) the shock artifact may obscure the response; (2) one must prove that the element is being stimulated directly, and not synaptically through other elements; (3) the anatomy of the individual cell being recorded from must be known to determine which parts of it are nearest to the stimulating electrode; (4) the part of the cell the action potential is being initiated from must be known.

There are 10 studies, listed in Table I, in which these problems have been satisfactorily solved and which yield quantitative data. The original papers should be consulted for the special methods used in each case. All of these studies used a monopolar electrode to deliver pulses of current. In 4 of these studies the neural element involved was a cell body with attached axon and dendrites and the stimulating electrode was on the side opposite to the axon. The 6 other studies are of myelinated fibers.

The results of these studies are plotted in Fig. 1. The two lines for each study give the range of values obtained for different fibers (see legend to Fig. 1). The results have been normalized in two ways. All have been recalculated for a $200-\mu \mathrm{sec}$ pulse. When strength-duration relations were determined, this relation was used for the normalization. When it had not been determined, the conversion factor listed in Table I was estimated, based on the results in section (C) (below). In some of these studies the stimulating electrode tip was completely surrounded by CNS so that current flowed radially in all directions - in spherical symmetry. In other studies the electrode was on the surface, and current flowed only in hemispherical symmetry. The currents in the hemispherical symmetry group were doubled to make them com- 


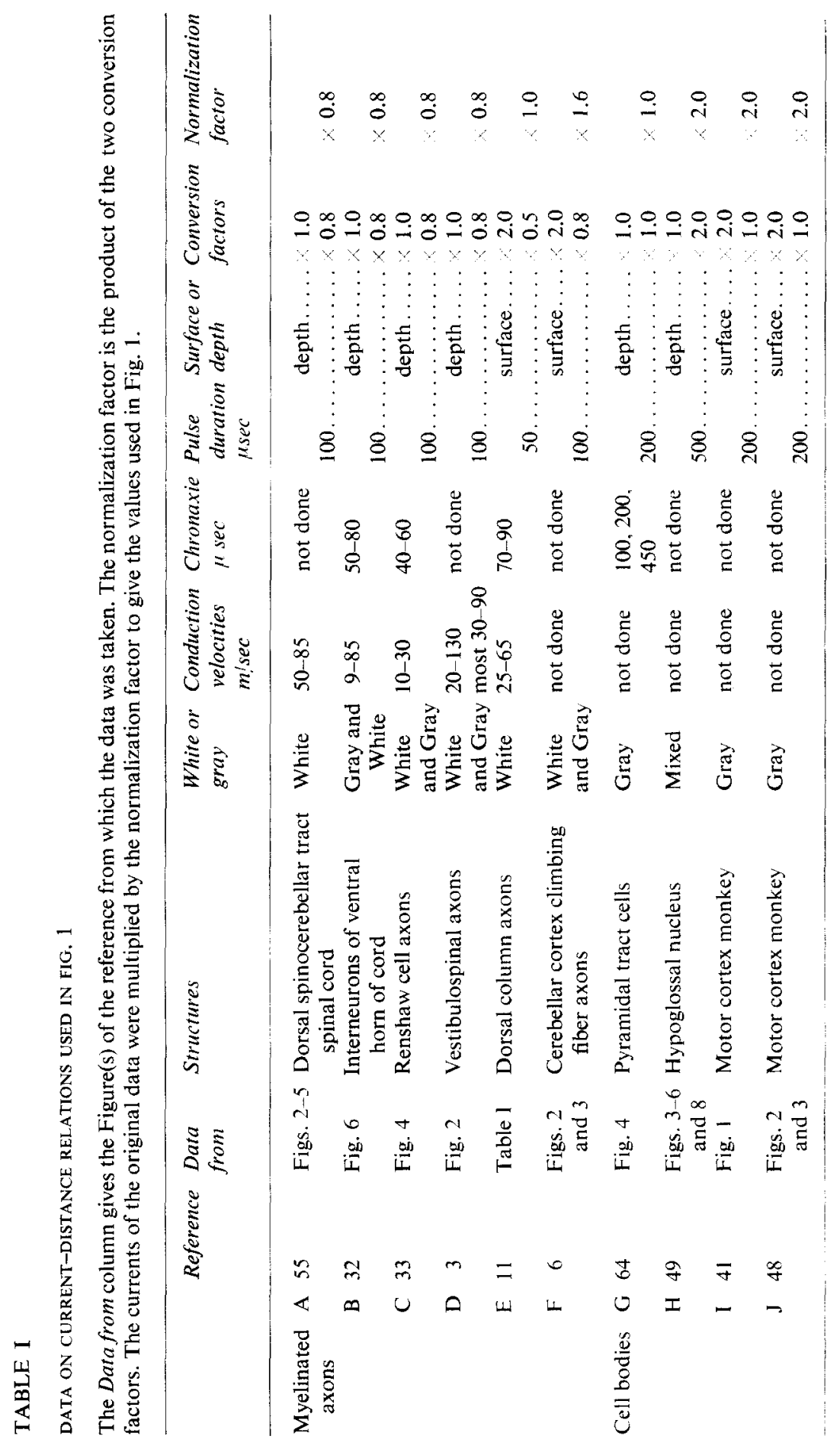




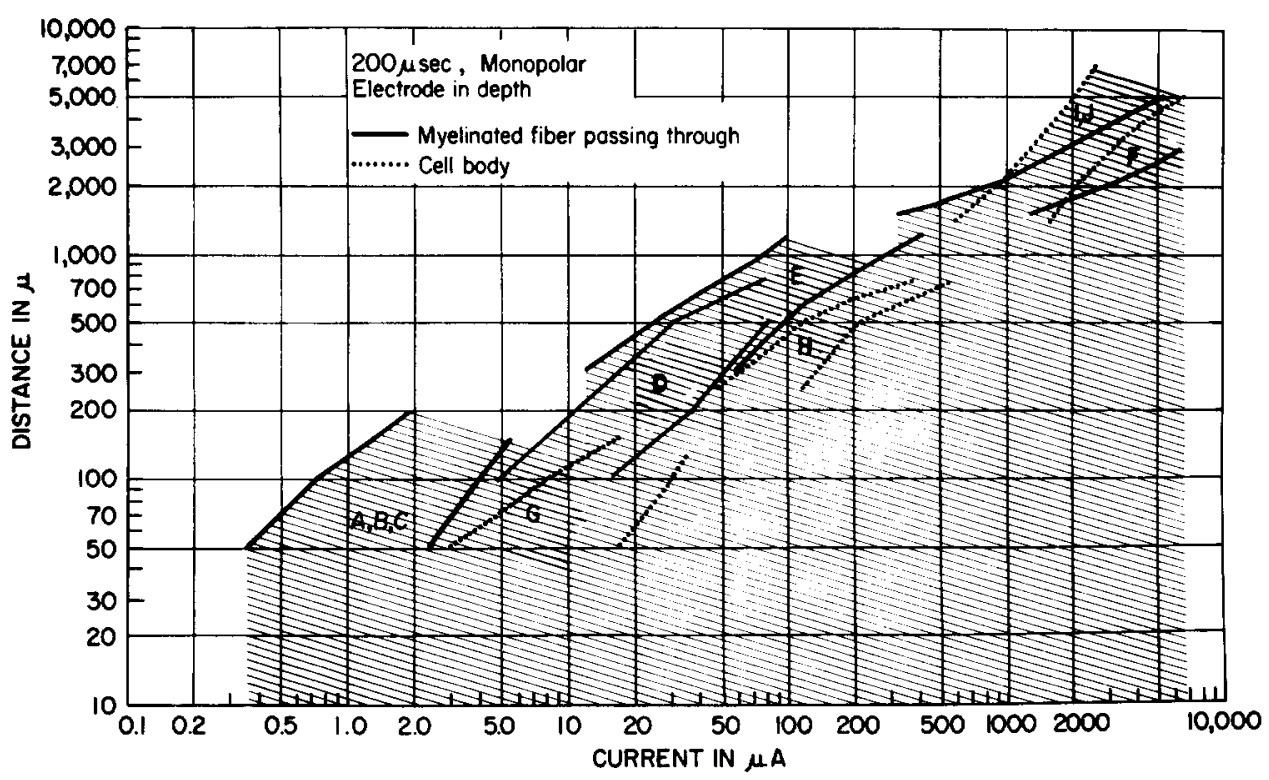

Fig. 1. Log- $\log$ plot of current-distance relations. All the data of studies A, B and C of Table I fall between the two lines on either side of the label 'A, B, C'. Similar labeling is used for the other studies. The entire range of data reported is plotted for all studies except study $E$. In study $E$ the currents plotted are the means of the groups of axons with the greatest conduction and the mean of the group of fibers axons with the slowest conduction velocity plus or minus one standard deviation. In study A the distance given is to the nearest node of Ranvier. In studies $I$ and $\mathbf{J}$ the distance was calculated by triangulation to a point $1 \mathrm{~mm}$ below cortical surface. In study $\mathrm{F}$ the distance to the site stimulated was assumed to be $1 \mathrm{~mm}$ from the best point, as the authors discuss on p. 45 of their study ${ }^{6}$. In study $E$ the conduction velocities were determined for each axon. In studies A, B, C and a range of presumably typical conduction velocities is reported. In studies $\mathrm{F}-\mathrm{J}$ conduction velocities are not reported. From figures in the text the following conduction velocities can be estimated: $\mathrm{G}, 20$ and $36 \mathrm{~m} / \mathrm{sec}$; $\mathrm{I}$, about $100 \mathrm{~m} / \mathrm{sec} ; \mathrm{J}, 20$ and $36 \mathrm{~m} / \mathrm{sec}$. All the data is for cathodal pulses except for studies $I$ and $J$ which are for either anodal or cathodal. However, in $\mathbf{I}$ and $\mathbf{J}$ there is little difference between cathodal and anodal pulses. Therefore, a single $200 \mu \mathrm{A}$ pulse from a monopolar cathode may stimulate up to the distances covered by the hatched area. One should know whether a cell body with axon, or an axon passing through the area is stimulated for further qualification of the use of this figure. One should know conduction velocity of the axon for yet further qualification.

parable with the spherical symmetry group. No attempt has been made to normalize for the differences in resistivity between gray and white matter. The data of Fig. 1 were arbitrarily cut off at a $50 \mu \mathrm{m}$ distance, because the errors become large with small distance. The original papers should be consulted for data on distances less than $50 \mu \mathrm{m}$. When very near a node of Ranvier, currents as small as $0.1 \mu \mathrm{A}$ may stimulate a fiber ${ }^{32}$.

There is a large variability in each study. BeMent and Ranck ${ }^{11}$ showed that the greater the conduction velocity of an axon, the less current it took to stimulate it at a given distance from a stimulating electrode, just as in the peripheral nervous system. Jankowska and Roberts ${ }^{32}$ and Roberts and Smith ${ }^{55}$ give anecdotal data consistent with this. Similar data were not obtained in the other studies, but it seems very likely that variation in fiber size explains part of the variability from cell to cell. There 
is another source of the variability in stimulation of myelinated fibers. The distance from stimulating electrode to the nearest node of Ranvier is the significant distance. However, the shortest distance from electrode to fiber was measured except in the study of Roberts and Smith ${ }^{55}$. The distance to the nearest node of Ranvier will vary randomly depending on where the electrode lies in the internode of each fiber. The distance to the nearest node will be equal to or greater than the shortest distance to the axon.

The data from the 4 studies of stimulation in the vicinity of a cell body $(\mathrm{G}-\mathrm{J}$ of Table I) all fall between two straight lines. These data were obtained in different kinds of neurons in different parts of brain, and there was almost no overlap in the current or distance ranges studied. Nevertheless, the linear log-log plot suggests that there is a systematic relationship which can be generalized to stimulation in the vicinity of other cell bodies in other parts of mammalian CNS. The data from the 6 studies of stimulation of axons passing through an area do not fall into as orderly a relation, but still suggest a general relation in all parts of mammalian CNS. The most serious discrepancy is between study $\mathrm{D}$ and studies $\mathrm{A}-\mathrm{C}$.

More than a 10,000-fold range of current, and more than a 100-fold range of distances are covered by these data. These data include almost the whole range of currents and distances used in experimental and clinical practice with intracranial electrodes so that Fig. 1 is of practical value. Consider the following example as an illustration of its use. A $200-\mu \mathrm{sec}, 100-\mu \mathrm{A}$ pulse passed from a monopolar cathode (Fig. 2) will stimulate axons with high conduction velocities (about $65 \mathrm{~m} / \mathrm{sec}$ ) which pass through a shell with a $1200 \mu \mathrm{m}$ outer radius centered at the electrode tip. Some

$200 \mu \mathrm{sec}$ pulse

$100 \mu \mathrm{A}$ cathodal

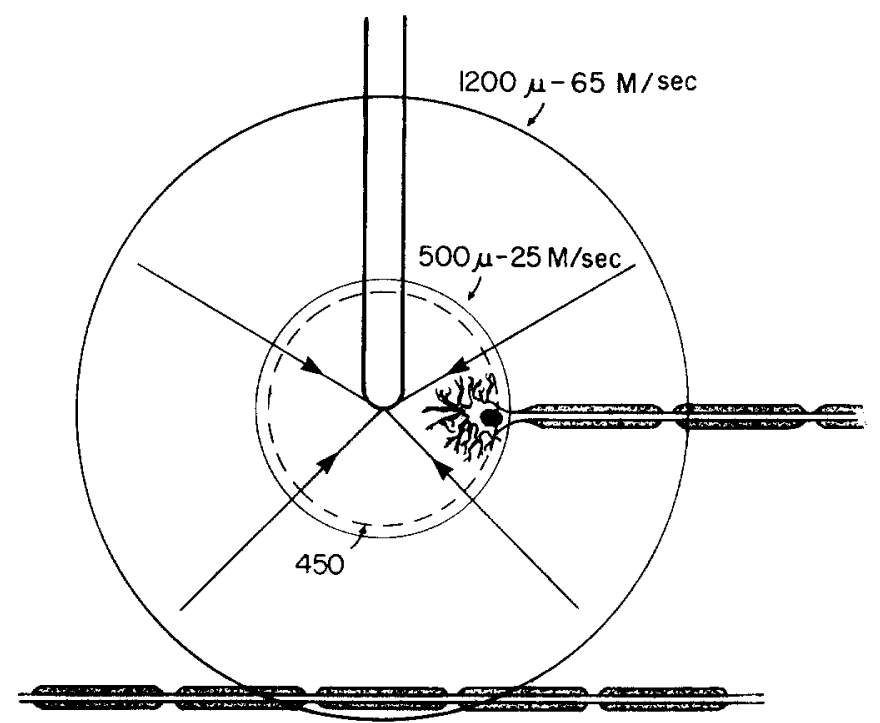

Fig. 2. For use in explaining the use of Fig. 1. See text. 
axons which pass into the inner core of the shell, close to the cathode, will not be stimulated (see $(B)$ below). Axons with lower conduction velocities (about $25 \mathrm{~m} / \mathrm{sec}$ ) passing through a shell with a $500 \mu \mathrm{m}$ outer radius will be stimulated. Neurons whose cell bodies are in a shell of $250 \mu \mathrm{m}$ outer radius and which have conduction velocities of about $10 \mathrm{~m} / \mathrm{sec}$ or more will also be stimulated. Some neurons which are as far as $450 \mu \mathrm{m}$ from the electrode will also be stimulated.

Data on current-distance relations for other neuronal elements do not exist. However, it seems likely that myelinated axons passing through an area and cell bodies with myelinated axons in an area are stimulated much more readily than any other elements.

Some isolated points on a current-distance curve can be estimated from other data. Merrill ${ }^{44}$ gives current-distance relations for a single fiber which are in good agreement with Fig. 1. Wise ${ }^{75}$ has results suggesting that $25 \mu \mathrm{A}$ of $60 \mathrm{~Hz}$ sine wave current stimulates up to distances of about $120 \mu \mathrm{m}$ in lateral hypothalamus. This would be in agreement with the results of Fig. 1 if he were stimulating small fibers. Baldissera et al. ${ }^{7}$ find that a $200-\mu \mathrm{A}, 200-\mu \mathrm{sec}$ pulse from a monopolar cathode stimulates axons of the rubrospinal tract with conduction velocities of about $80-100$ $\mathrm{m} / \mathrm{sec}, 1-1.5 \mathrm{~mm}$ away; $50 \mu \mathrm{A}$ stimulates $200-500 \mu \mathrm{m}$ away. These results are in reasonable agreement with Fig. 1. Fuller ${ }^{23}$ estimates that $400-\mu \mathrm{A}, 300-\mu$ sec pulses stimulate axons in brain stem reticular formation with conduction velocities of from 2 to $35 \mathrm{~m} / \mathrm{sec}$ within $300 \mu \mathrm{m}$ of his electrode. Because of the low conduction velocity, these results are in reasonable agreement with Fig. 1.

The data in Fig. 1 include only a limited range of conduction velocities and some of these findings have not been replicated by independent workers, so the data should only be considered approximate. Other qualifications of its use will be developed below (especially the 'anodal surround' phenomena of section $(B)$ ). Nevertheless, Fig. 1 should be of practical use. More of these studies should be done with closer attention being paid to conduction velocity as a source of variation in the current-distance relation.

\section{(B) Effects of inward current}

With extracellular stimulating electrodes, for any outward current that locally depolarizes a fiber there must be an inward current elsewhere that will hyperpolarize the fiber. This has practical implications, one for the case of a monopolar cathode and a different one for the case of bipolar electrodes.

A fiber is depolarized near a monopolar cathode by outward current, and hyperpolarized on either side by inward current ('anodal surround') (Fig. 3). The inward current is spread out over a larger area than the outward current, so the magnitude of hyperpolarization will in general be less than the magnitude of the depolarization. An action potential generated at the depolarized site can propagate through a hyperpolarized site if the hyperpolarization is not too large. However, if the hyperpolarization is large enough, it may prevent an action potential from propagating through the hyperpolarized site.

While studying a peripheral nerve fiber, Katz and Miledi ${ }^{35}$ showed that currents 

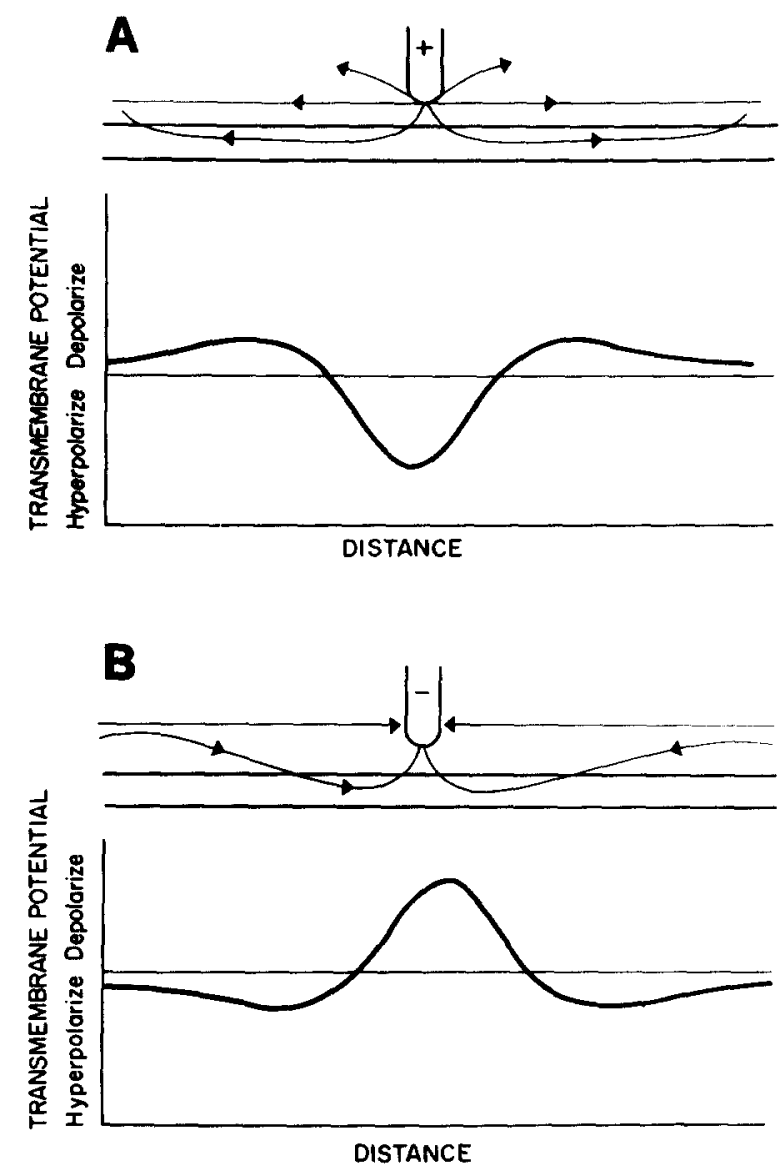

Fig. 3. Current flow in a fiber when current is passed from a nearby monopolar electrode. A: from an anode. B: from a cathode. The fiber is depolarized where there is outward current across the cell membrane of the fiber. The other electrode in each case is not shown and is a large distance away.

from an extracellular cathode 2 or 3 times threshold for initiating an action potential would fail to generate a propagated action potential. Their results are no doubt due to the anodal surround. Similar results have been obtained by others working in CNS with currents about $8-10$ times threshold ${ }^{32,55}$. Therefore, paradoxically, near a stimulating extracellular cathode where current density is highest, some fibers may not be stimulated with a given current, even though these fibers would be stimulated if less current was passed or if the fibers were further from the electrode. Thus the axons of a given conduction velocity which are stimulated are those which pass through a shell around a monopolar cathode, and do not enter the inner core (Fig. 4). There presumably are no such phenomena around a monopolar anode. I know of 110 comparable phenomena for stimulation near a cell body; it should be done.

An increase in current above threshold can be achieved by increasing the current or by moving the electrode closer to the axon. The data in Fig. 1 do not give a good numerical value to this equivalence over an 8 -fold range in current. However, 


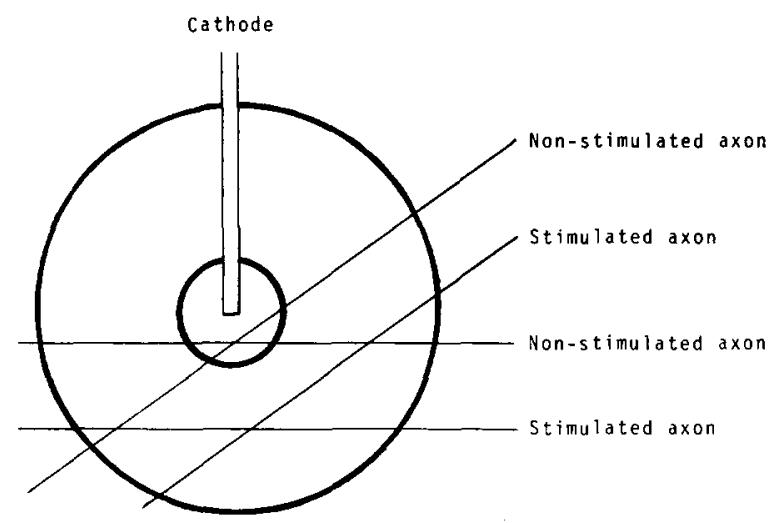

Fig. 4. The anodal surround effect. Axons passing through an inner sphere are not stimulated. Axons passing through a shell and not entering the core are stimulated. There is a $1: 4$ ratio between the inner and outer radii of the shell for reasons given in the text.

as an example, let us say that an 8 -fold increase in current is equivalent to a 4 -fold decrease in distance (see Bean ${ }^{10}$ for a further discussion of this). Therefore, the radius of the sphere of non-stimulated axons may be as large as one-fourth the outer radius of the shell of stimulated axons. The ratio of inner and outer radii of the shell may be about $1: 4$. The absolute dimensions will depend on the current passed and the conduction velocity of the axon. For a given amount of current the dimensions will be larger for large diameter axons than for smaller ones. This leads to the paradoxical conclusion that for a given amount of current there will be a zone close to the electrode in which small diameter fibers are stimulated and larger diameter fibers are not.

When bipolar electrodes have tips in the same orientation as a fiber, a fiber will be depolarized under the cathode, and hyperpolarized under the anode. If the hyperpolarization is large enough, an action potential initiated under the cathode may not be able to propagate through the region of hyperpolarization. If this is the case, the action potential will propagate in only one direction.

Szabo and Milner ${ }^{68}$ and Szabo et al. ${ }^{70}$ have demonstrated phenomena in selfstimulation of rat which may have this as the basis. They are able to use these facts in an analysis of what direction of propagation is most important in self-stimulation.

\section{(C) Strength-duration relations}

When stimulating current is being passed in constant current pulses, the relation between the amount of current and the duration of the pulse which give the same response yields the well known strength-duration curves. Rheobase current is the amount of current necessary to stimulate with a long duration pulse. Chronaxie is the time on the strength-duration curve for twice rheobase current. Many strengthduration curves fit the empirical equation, $I=I_{r}(1+C / t)$, where $I$ is the current (or voltage), $I_{r}$ is rheobase current, $t$ is time, and $C$ is chronaxie. Chronaxie is often about 0.7 the time constant of the membrane (the time constant of the membrane is the membrane resistance times the membrane capacity). 


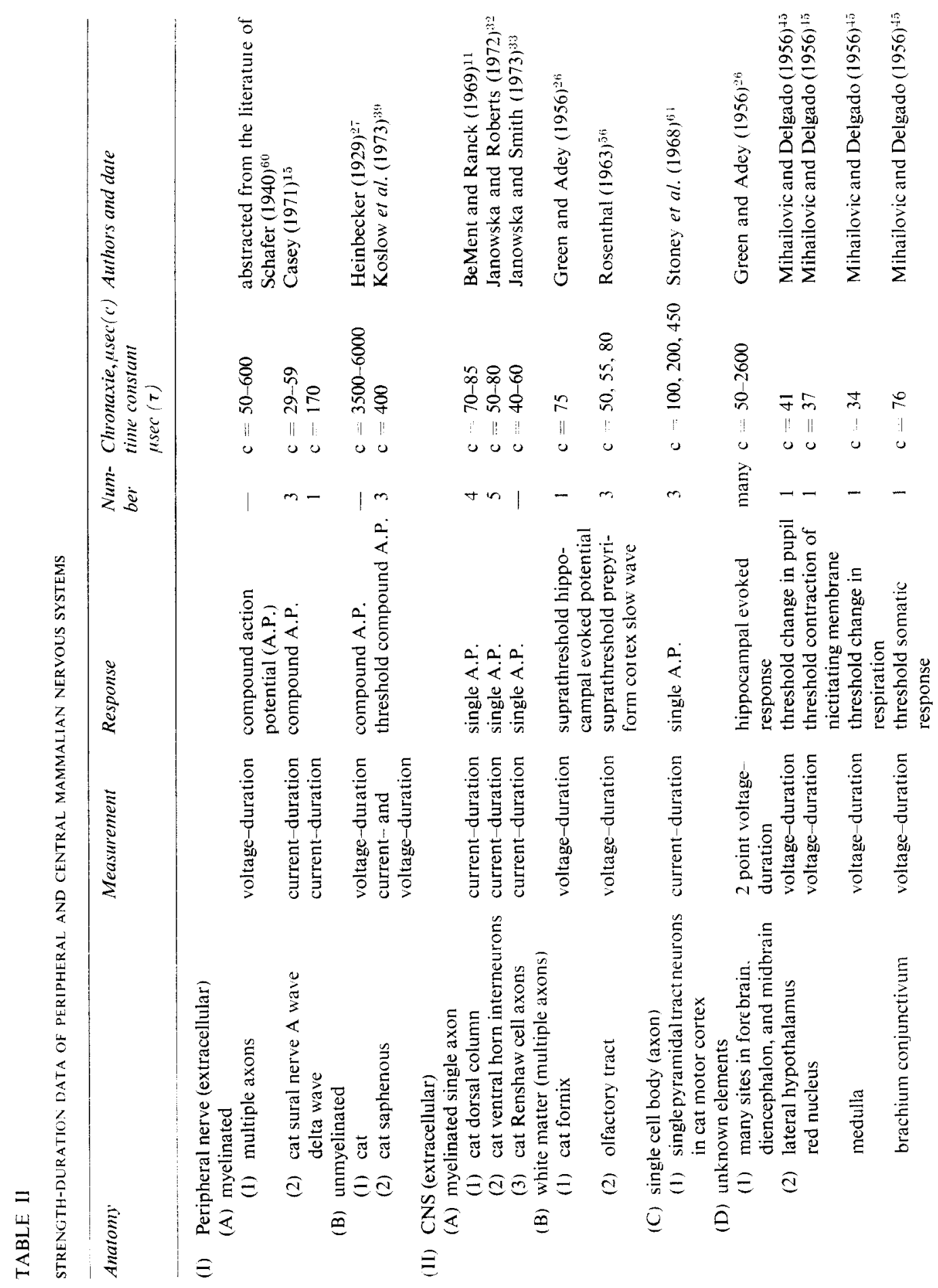




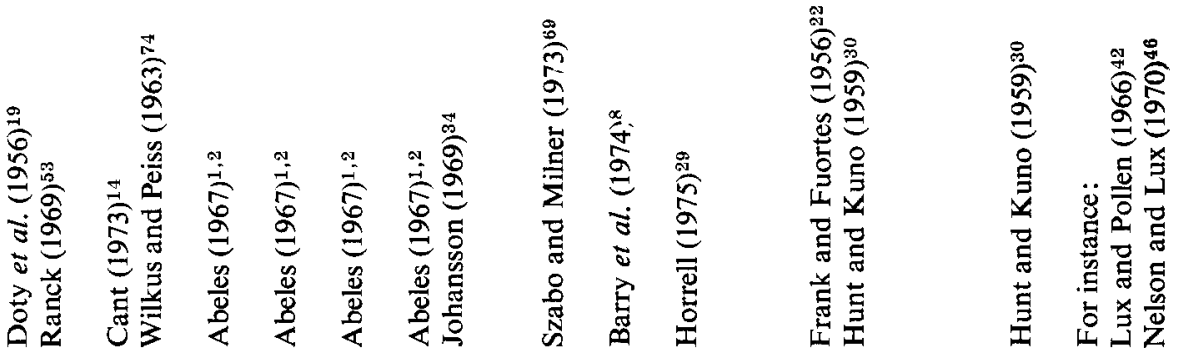

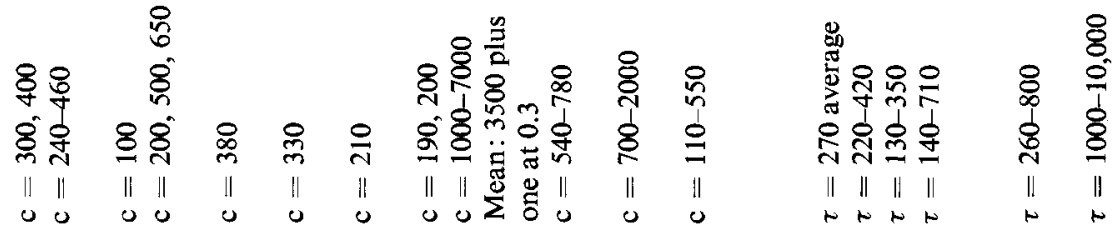

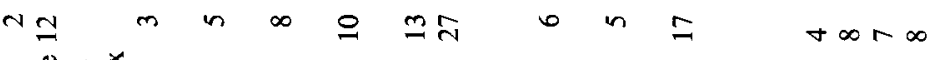

㲾黄希

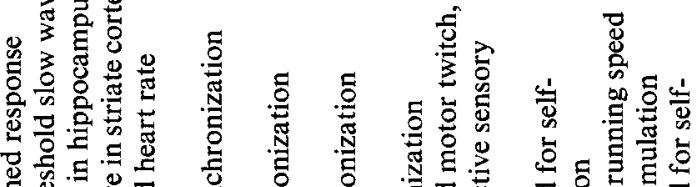

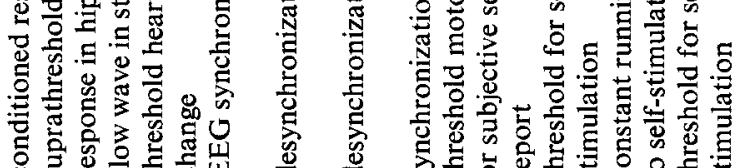

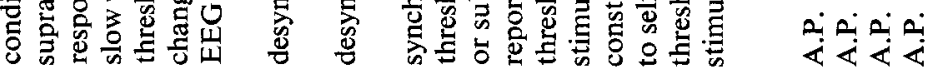

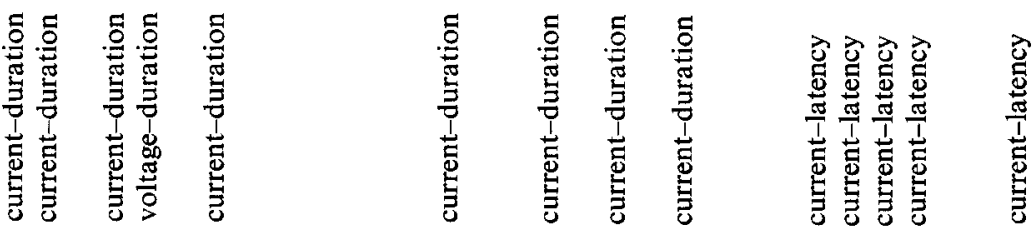

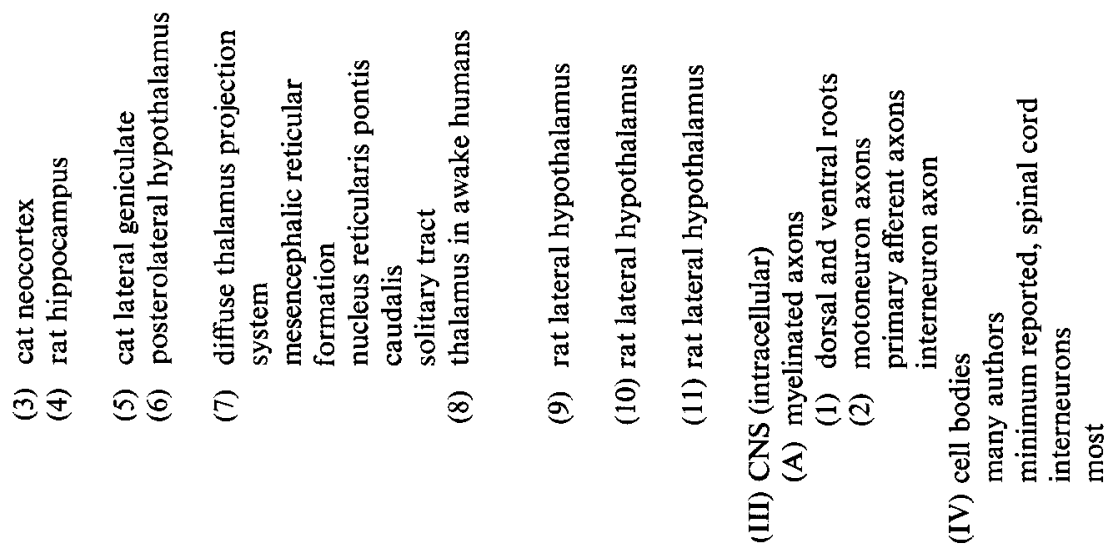


Table II lists values of chronaxie or time constants of both peripheral and central nervous system in mammals. One should be cautious about drawing conclusions from these data, for there are a small number of them from different investigations over a period of many years. The purposes of the measurements varied widely. On the other hand, the measurement is a fairly easy one to make; therefore, most of the data are probably good. Many generalizations can be drawn from Table II.

(1) All chronaxies of extracellular stimulation of single CNS myelinated fibers or of white matter (where only axons could have been stimulated) are 40-100 $\mu \mathrm{sec}$. Time constants or chronaxies from fibers measured intracellularly are 130-710 $\mu \mathrm{sec}$. It is not clear why there is this marked difference. The differences in current flow should give only minor differences in the measurement. The strength-latency method used in intracellular studies may give durations which are longer than those obtained with other methods. Intracellular recording and stimulation may have injured the fiber. Both sets of data are so small that the difference may simply be due to sampling.

The chronaxies of peripheral myelinated fibers can be as short as $29 \mu \mathrm{sec}$, but may be up to $700 \mu \mathrm{sec}$. The longest values come from the oldest literature. I have not been able to find any extensive study on mammals since 1940. These studies should be repeated.

Current may flow into one part of a neuron and out of another part where it stimulates. Yet the time constant of the unstimulated element may largely determine the time course of current flow through the stimulated element. Therefore, while current may flow through more than one part of a cell, an agreement between time constant of an element and a chronaxie of stimulation should suggest only that current flows through the element, not that the element is directly stimulated.

There is no suggestion that any elements other than nodes of Ranvier have time constants of $30-200 \mu \mathrm{sec}$. Therefore, when stimulating where many elements are present if the chronaxie is $30-200 \mu \mathrm{sec}$, and especially if it is $30-100 \mu \mathrm{sec}$, it seems likely that current is flowing through nodes of Ranvier. It cannot be concluded that nodes of Ranvier are being stimulated, although it should be strongly suspected.

(2) The time constant of the cell body and dendrites of most neurons, as determined with intracellular micropipettes, is in the 1-10-msec range. The Hunt and Kuno study ${ }^{30}$ is the only one I know of in which values much less than $1 \mathrm{msec}$ were found. Analysis of impedance of neocortex is an indirect way of determining membrane time constant and it also yields values in the 1-10-msec range ${ }^{51,52}$.

Only two of these studies have chronaxies greater than $1 \mathrm{msec}^{\text {. The Johansson }}{ }^{34}$ study is the only study with chronaxies of extracellular stimulation greater than $2 \mathrm{msec}$ and many of his values are much larger than this. His strength-duration curves have a different shape from that of most data and do not fit with the standard empirical equation. Barry et al. ${ }^{8}$ find chronaxies of $700-2000 \mu \mathrm{sec}$ for self-stimulation in lateral hypothalamus.

Anecdotal comments in two other studies suggest comparable chronaxies. MacLean and Ploog ${ }^{43}$ find some parts of brain can be 'most effectively' stimulated to produce penile reaction with about $1.0-\mathrm{msec}$ pulses, and other structures with 
$10-50-\mu$ sec pulses. Ajmone Marsan ${ }^{4}$ says epileptic form afterdischarge is most readily elicited by pulses of 0.5-10 msec. Perhaps current flow through cell bodies or dendrites was involved in the stimulation with long pulses in these cases.

Most of the chronaxies for stimulation of unknown elements are in the 200-700$\mu \mathrm{sec}$ range. There is no simple explanation for this. It is discussed further in the Discussion section $(A)$ below.

Data from strength-duration curves are clearly useful in determining what is stimulated in brain. We need more data on time constants and chronaxies of known elements of the central and peripheral nervous system. Strength-duration curves should be routinely determined in electrical stimulation of brain; they can be done easily.

\section{(D) Polarity of the stimulus}

\section{(1) Myelinated fibers passing by an electrode}

Two studies have compared anodal versus cathodal currents in the stimulation of myelinated fibers. One study found that it required 3.19-7.7 (mean 4.57) times as much current from an anode as from a cathode to excite the axon ${ }^{11}$. The other study found 1.0-3.2 times as much anodal current necessary ${ }^{6}$. The reason that a monopolar cathode is more effective than a monopolar anode when stimulating an excitable fiber passing by an electrode is illustrated in Fig. 3.

\section{(2) Near cell bodies}

Starting with Fritsch and Hitzig, many workers have shown that monopolar stimulation of the pial surface of motor cortex is often more effective with an anode than a cathode. Hern et al. ${ }^{28}$ have shown that a monopolar pial anodal may stimulate pyramidal cells directly. This is probably because the axon and perhaps some adjacent regions of the cell body have a much lower threshold than dendrites and cell body (if indeed these can fire action potentials at all). Anodal current enters (and hyperpolarizes) dendrites, and leaves and depolarizes the axon or cell body ${ }^{50}$ (Fig. 5). Note that the voltage gradient around the axon or cell body is much less than that around the dendrites, but that axon or cell body is still the element stimulated. The difference between threshold for anodal and cathodal pulses is usually less than 2-fold ${ }^{22}$.

Porter $^{49}$ reported studies of direct stimulation of single hypoglossal neurons with a monopolar anode or cathode at various distances from the cell. The lowest threshold was always to cathodal stimulation near the axon, with the threshold currents decreasing as the electrode approached the axon. When the stimulating electrode was on the opposite side of the cell body from the axon, cathodal stimulation usually had a lower threshold than did the anodal. In a few cases, the anodal threshold was lower, presumably for the same reason as in neocortex. The differences in currents required was less than 2 -fold in all cases. Porter concludes that it is always the axon which is being stimulated.

Stoney et $a l .{ }^{64}$ have stimulated single pyramidal tract neurons with monopolar microelectrodes in the vicinity of the cell body. The lowest threshold is for cathodal 


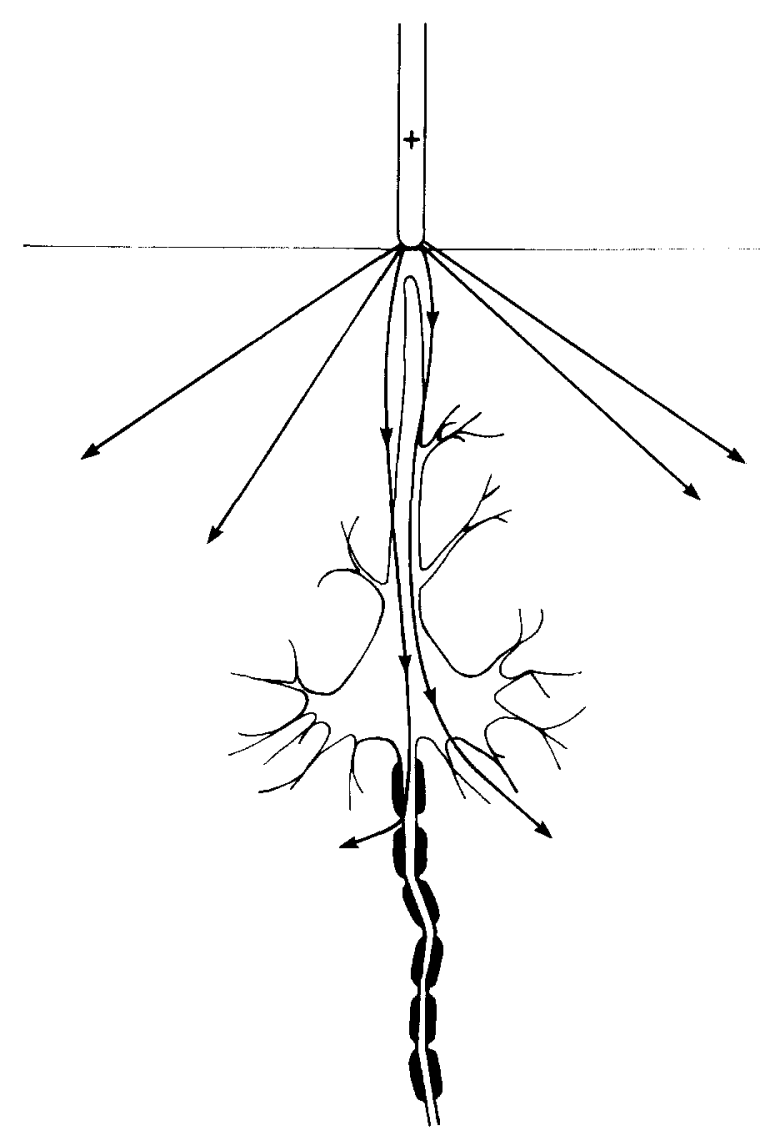

Fig. 5. Presumed basis for stimulation of some neocortical cells with an anode on surface. The current enters apical dendrites (and hyperpolarizes them) and leaves the axon and depolarizes it.

stimuli near the cell body. Anodal currents of greater than 1.8-12 times cathodal were necessary.

Valenstein and Beer ${ }^{72}$ and Wetzel ${ }^{73}$ have shown that self-stimulation of lateral hypothalamus of rats requires less current from a monopolar cathode than from an anode.

These issues are discussed more fully in $(A)$ of the Discussion below.

\section{(E) Electrode orientation}

In 1927 Rushton ${ }^{59}$ clearly demonstrated that it was the extracellular voltage gradient in the direction of an axon which was the salient parameter for stimulation. If the voltage gradient was entirely transverse to the axon, the axon could not be stimulated (Fig. 6).

Rudin and Eisenman ${ }^{58}$ stimulated dorsal columns of cat in an in vitro preparation with bipolar electrodes, and recorded a compound action potential. If the electrodes had a transverse orientation to the axons, 4 or 5 times as much current was necessary in order to get the same result as with a longitudinal orientation. 


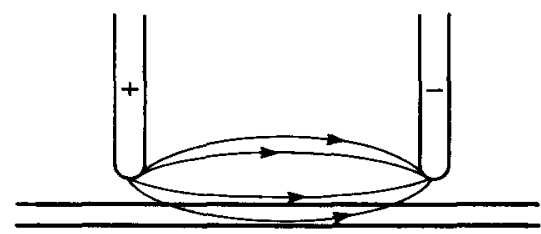

LONGITUDINAL

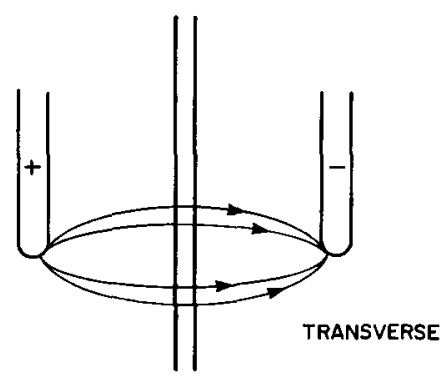

Fig. 6. Longitudinal versus transverse current flow in a fiber.

Cole and Baker ${ }^{16,17}$ studied transverse and longitudinal current flow associated with extracellular fields in squid giant axon. Fatt ${ }^{20}$ and Falk and Fatt ${ }^{21}$ studied transverse and longitudinal current flow in striated muscle. The issue has received extensive theoretical treatment in these papers $16,17,20,21$ and by Ranck ${ }^{52}$.

To my knowledge Szabo and Milner ${ }^{67,68}$ have been the only ones to be concerned with this issue in in vivo stimulation of CNS. They found that in self stimulation of lateral hypothalamus in rats, a medio-lateral alignment of tip was more effective than anterior-posterior alignment.

\section{(F) Miscellaneous facts}

(1) Bennett ${ }^{13}$ has shown that on the pial surface of neocortex there are membranes with a resistance of $50-100 \Omega / \mathrm{sq} . \mathrm{cm}$, and with a time constant of $3.0 \mathrm{msec}$. This resistance is destroyed by a few minutes of exposure to air. This pial surface resistance will affect stimulation from electrodes on the surface. The extent of exposure to air should be reported in all cases of stimulation of neocortical surface; in fact, it is rarely reported.

(2) Accommodation of central axons and of cell bodies has been studied with intracellular micropipettes (for instance see refs. 61 and 71). Axons show substantial and rapid accommodation (within a few milliseconds). Some cell bodies accommodate rapidly; others accommodate slowly (only over periods of hundreds of milliseconds). (Point 2 of the summary of ref. 61 incorrectly summarizes the text.) There do not seem to be any data on accommodation in neurons in CNS with extracellular stimulation. This is especially unfortunate because of the frequent use of $60 \mathrm{~Hz}$ sinusoidal stimulating current, at which frequency accommodation would be expected to occur. Indeed the slow accommodation of central cell bodies as opposed to axons suggests 
the possibility that cell bodies are relatively more likely to be stimulated by $60 \mathrm{~Hz}$ sinusoidal stimulation. Post-hyperpolarization excitation can be shown in some CNS cell bodies with intracellular recording 5 . It occurs with extracellular stimulation of peripheral axons (anodal break phenomenon). There do not seem to be any data on its occurrence with extracellular stimulation of central axons, although one would not be surprised to find it with $60 \mathrm{~Hz}$ sinusoidal stimulation.

(3) The resistivity of gray matter is 4-6 times greater than cerebrospinal fluid ${ }^{51}$ and about 2-3 times less than the resistivity of white matter ${ }^{47,54}$. White matter is anisotropic ${ }^{47,54}$. These factors must be considered when calculating exactly what the pattern of current flow and the extracellular voltage gradient will be.

(4) Very small voltage gradients, which do not cause an action potential when they are turned on for brief periods, can affect the rate of firing of cells averaged over time when the currents pass for long times ${ }^{62,65}$. These 'polarizing' currents can be as small as $5 \times 10^{-10} \mathrm{~A}$ from a micropipette. Analyses of these phenomena are beyond the scope of this review.

(5) There are few useful data and little useful theory on the significant differences of different electrode configurations. Orientation II.E and anodal blocking II.B effects should be looked for whenever the experimenter is using something other than a monopolar electrode. These considerations may be part of the reason for the inconstant results of comparisons of monopolar versus bipolar electrodes ${ }^{63,72}$. Wetzel ${ }^{73}$ has pointed out that with side-by-side bipolar electrodes, the elements between the electrodes' tips are probably preferentially stimulated.

One finds frequent comments in the literature giving a rationale for various electrode configurations. Most of these seem to me to have no justification. In most cases we simply do not know what different electrode configurations do. (Some bipolar electrode configurations may be helpful in decreasing the stimulus shock artifact, but this can often be accomplished in other ways.)

\section{DISCUSSION}

\section{(A) The problem of cell bodies and 200-700 usec chronaxies}

There are two related problems in the interpretation of these data. What part of the cell is being stimulated when a neuronal cell body is near the stimulating electrode? Why do so many strength-duration curves from stimulation of gray matter have chronaxies of $200-700 \mu \mathrm{sec}$, and what elements are being stimulated in these cases? There are no elements of the central nervous system known to have time constants predominantly in the range of $200-1000 \mu \mathrm{sec}$. If stimulating current were to flow through both a nodal membrane and a cell body or dendritic membrane, the chronaxie in some circumstances might be intermediate between the chronaxies of each, in the $200-1000-\mu \mathrm{sec}$ range. However, in other circumstances the chronaxie would not be intermediate. For instance, if the net resistance across the dendritic membranes were much lower than across nodal membranes, the chronaxie would be very close to that of the nodal membrane. Because of the relatively large area of 
dendritic membrane, this might be the case. The data and theory currently available do not allow us to decide. Iansek and Redman ${ }^{31}$ suggest that the specific resistivity of the soma membrane could be as low as one-third of the dendritic membrane resistivity, which complicates the case even further.

As discussed in section II.D, in cases where a monopolar electrode is on the opposite side of the cell body from the axon and can stimulate the neuron with less anodal current than with cathodal ${ }^{49}$, it seems very likely that the stimulation is initiating the action potential in the axon or cell body. Most of the evidence for this comes from neocortex (for instance see refs. 25, 28, 40, 50 and 57). In a neuron whose dendrites could not generate an action potential, it could not be otherwise.

However, some dendrites can generate action potentials, and in some cases a monopolar electrode on the opposite side of the cell body from the axon can stimulate the neuron with less cathodal current than with anodal ${ }^{49}$, or there may be little difference in threshold currents between the two polarities. Also the small amount of data available on chronaxies when stimulating near cell body does not fit with what is known about the characteristics of the cell membranes ${ }^{64}$. Therefore, a generalization as to which part of the neuron generates an action potential when the electrode is near a cell body cannot be made. Gorman ${ }^{25}$ has shown differences between the response of pyramidal tract cells stimulated by surface anodal and cathodal currents, and has suggested that $d$ fferent polarities stimulated different parts of the cell. Other interpretations of his data are possible. The nature of stimulation around cell bodies is not clear. It would seem to be a problem that can be solved with current experimental methods. It has never been seriously examined theoretically.

There are other possible explanations for $200-700 \mu \mathrm{sec}$ chronaxies in gray matter. Perhaps nodes of Ranvier have different time constants in gray matter. The intracellular data suggest that this may be the case. Perhaps presynaptic endings, or unmyelinated fibers are being affected. Perhaps neurons which release neurotransmitters without action potentials (as in retina) are being affected.

For distances of less than $1 \mathrm{~mm}$ from an electrode, the data of Fig. 1 show that myelinated fibers passing through an area can be stimulated with less current than axons originating from cell bodies in the same area. However, the conduction velocities of the axons originating in the area were not well known in these studies, so it would not be proper to conclude that axons passing through are more readily stimulated. Furthermore, the data of Fig. 1 were obtained by different investigators on different preparations, so one must be careful about conclusions drawn from comparisons.

\section{(B) Theory}

There has been a great deal of work in the last 15 years on the solution of cable properties of neurons for the case of currents from intracellular electrodes or the case of activation of synapses. There has been almost no work on the solution of these cable properties for imposed extracellular currents. The theory of extracellular stimulation involves the same issues as the problem of where current flows in brain, and 
the theory of brain impedance. This theory has never been reviewed with the application of extracellular stimulation in mind. It will not be reviewed here, but a few useful points will be touched on.

The transmembrane depolarization which causes action potentials in extracellular stimulation is largely due to the extracellular voltage becoming more negative. Changes in intracellular potential are much smaller than extracellular. A highly localized extracellular voltage gradient may not be effective for stimulation. It is the absolute difference between the extracellular voltages on the surface of the same neural element within distances of the order of a length constant or less which are important. (A length constant for myelinated fibers is a constant in a difference equation rather than in a differential equation as in the case for unmyelinated processes. However, the two cases are quite analogous, hence the use of the same term. A length constant for myelinated fibers is almost two internodal lengths. See BeMent and Ranck ${ }^{11,12}$ for data and a review of internodal lengths in the CNS.) Therefore, if one is using bipolar electrodes, in order to stimulate an element with the least amount of current, the tips should have the same orientation as the element and be separated by about the length constant of the element one wants to stimulate.

Since it is extracellular voltage gradients which stimulate, we want to know stimulating current. The voltage applied to the stimulating electrodes is usually not a useful parameter. Most of this voltage difference occurs at the interface of electrode and tissue.

A simple approximation can be derived for the case of fiber in a constant extracellular field ( $g r a d V_{0}$ constant) in the direction of the fiber. Grad $V_{0}$ is rarely constant, but is often a simple approximation of the case. For the DC case (i.e., a pulse duration which is more than twice the time constant of the membrane) the maximal depolarization is $\operatorname{grad}\left(\mathrm{V}_{0}\right) \lambda \tanh b / 2 \lambda$, where $\lambda$ is the length constant, $b$ is the length of element, and tanh is the hyperbolic tangent (a function which is about equal to its argument for quantities less than 0.5 , and then goes to a maximum of 1.0 as the argument increases further). This expression is derived in one step from equation 6 in ref. 52. For $b / 2 \lambda>2$ (a long fiber), the depolarization is approximately grad $\left(V_{0}\right) \lambda$. For $b / 2 \lambda<0.5$ the depolarization is approximately grad $V_{0} b / 2$. For pulse durations which are less than twice the membrane time constant the depolarization is less. The accuracy of the approximation of considering grad $V_{0}$ constant around a monopolar stimulating electrode is discussed by BeMent and Ranck ${ }^{12}$. The equation can be directly applied to the case of stimulation of the retina with radial transretinal currents $^{38}$.

The stimulation of myelinated fibers with a monopolar electrode is the only other case of stimulation which has been examined theoretically in a practical way. This case has, however, been worked out in some detail by BeMent and Ranck ${ }^{12}$ and Bean ${ }^{9,10}$. Abzug et al..$^{3}$ put this theory to practical use.

The classical analyses of Cole and Baker (e.g., refs. 16 and 17) are essential background for any theoretical work. Analyses of transverse and longitudinal current flow is also useful $16,17,20,21,52$. There is other theoretical work which has not yet led to useful results (e.g., refs. 36 and 37). 
The overall pattern of extracellular voltage will be a function of the electrode configuration, and also a function of the resistivities of the surrounding tissues. When the tissue does not have a homogenous resistivity, as is the case when stimulating near cerebrospinal fluid or when near both white and gray matter, the patterns of voltage gradients with different electrode configurations can be very complicated, but nevertheless solvable.

To determine what will be stimulated one must know, in addition, the electrical properties and geometry of the neural elements in the area.

What is stimulated from a given electrode(s) will thus depend on (a) the electrical properties and anatomy of the neural elements, (b) the distance and orientation of the neural elements relative to the electrode(s), (c) the resistivities of the tissue, (d) the pattern of current flow which is determined by configuration of electrode(s) and resistivities of the tissue and (e) the current passed (its shape, duration, and magnitude). To speak of 'current spread' or to consider only current density in attempting to decide what is stimulated is not adequate. Data and theories directly dealing with all these aspects would be useful.

\section{(C) Studies which should be done}

(1) The electrophysiology of finely myelinated and unmyelinated axons in the CNS should be studied. At present there is no data at all. Current-distance relations, current-duration relations, conduction velocities, accommodation, post-hyperpolarization excitation, refractory periods and effects of polarity, orientation and inward currents could possibly be determined with methods presently available. These data would allow us to infer time constants, membrane resistance, and, less accurately, length constants. The study of characteristics of electrical stimulation is one way to study basic electrophysiological properties. The pyramidal tract in the brain stem might be a useful preparation.

(2) The electrophysiology of cell bodies, dendrites, and attached axons, in response to imposed extracellular currents should be extensively studied experimentally and theoretically. The experiments of Stoney et al. ${ }^{64}$ could be repeated. At many locations of the stimulating electrode in the vicinity of the cell body one should study threshold currents, strength-duration relations, accommodation, post-hyperpolarization excitation, refractory periods, effects of different polarities, and blocking effects of large currents. Conduction velocities should be accurately determined for each cell. The effects of different voltage gradient orientations could be determined with the same preparation. These data should generate quantitative theoretical interpretation, which would in turn generate more experiments. Here again study of extracellular stimulation is a good way to study electrophysiological characteristics of some parts of neurons.

(3) The electrophysiology of synaptic endings should be studied. Strengthduration relations, effects of different polarities, accommodation, post-hyperpolarization excitation can probably be determined with methods available now. Perhaps some current-distance relations could be determined. 
(4) Accommodation and post-hyperpolarization excitation should be studied in all kinds of elements with extracellular stimulation. There are large differences in accommodation between cell bodies and attached processes and axons of passage ${ }^{61,71}$. This should be useful in differential stimulation.

(5) Refractory periods of CNS neurons for extracellular stimulation should be measured. There are different refractory periods of different action potential generating sites as determined with intracellular recording. Are there differences between cell body and axon? Szabo et al. ${ }^{66}$ have measured refractory periods and fiber diameter of some central tracts and suggest that there is a systematic relation, as there is in peripheral nerve. Behavioral methods for measuring presumed 'refractory periods' have been used ${ }^{18}$, although these conclusions have been questioned (e.g., ref. 65). Measurement of refractory periods may be a useful way to determine what is stimulated, but not at our present state of knowledge.

(6) Theoretical work on voltage gradients in tissue with varying resistivity and with different electrode configurations is needed. The problem of stimulation of cell body and adjacent processes needs extensive theoretical treatment. The theory behind all stimulation should be extended, with a clear eye to practical application. The consequences of different electrode configurations and wave shapes of current are very practical issues needing theoretical attention. Those doing the theoretical work should remember that many workers who stimulate CNS do not have strong physical or mathematical backgrounds, yet these workers should be the major audience for theoretical work.

(7) More work should be done on strength-distance relations (with measurements of conduction velocity), outward current blocking effects, strength-duration relations, polarity and orientation effects and pial effects. Many of the conclusions of this review are based on a small number of observations which may be an atypical sample. Strength-duration relations on peripheral nerve should be repeated using modern methods.

(8) Differential stimulation of cell bodies and their adjacent processes, as opposed to stimulation fibers of passage, or pre-synaptic endings or perhaps other elements has never been achieved. Differential stimulation of small axons rather than large axons in CNS has also not been achieved. To be able to do any differential stimulation, or even to know more clearly what was being stimulated would be of great value. The data covered in this review suggest that there may be important differences in stimulation properties between cell bodies with their adjacent processes and axons of passage in strength-distance relations, inward current blocking, strengthduration relations, orientation and polarity effects, accommodation, and effects of configuration of voltage gradient. These differences suggest many possible ways which might be useful in differential stimulation. There are differences in stimulation properties of large and small diameter axons in current-distance relations, inward current blocking, and length constants (and hence effects of electrode separation). These possibilities should by systematically tried. We do not know anything about stimulation properties of unmyelinated axons or presynaptic endings, but no doubt there are differences from other elements which might make differential stimulation possible. 
(D) Some practical suggestions for electrical stimulation of mammalian CNS in 1975

(1) Use pulses of current from monopolar electrodes. Most of the interpretable data is for this mode of stimulation. Other electrode configurations and other current wave shapes will probably be useful in the future. However, at present there is too little known about them to justify their use in most cases. Measure and report stimulating current, not voltage.

(2) Use the current-distance relation data which are known (Fig. 1).

(3) Use the current-duration relation data which are known. Use 50- $\mu \mathrm{sec}$ pulses if one wants to stimulate myelinated fibers.

(4) Do current-duration curves routinely. Even a 3-point curve (say at $1 \mathrm{msec}$, $200 \mu \mathrm{sec}$, and $50 \mu \mathrm{sec}$ ) would be of value. In many cases it would be easy to do.

(5) Attend to other known facts such as inward current blocking, accommodation, and effects of polarity orientation and pia. Report the orientation of the electrode tips when using bipolar electrodes. Report any exposure of the pial surface to air.

\section{ACKNOWLEDGEMENTS}

Supported by Grant NS-10970 from the National Institutes of Health.

Drs. Gabriel Frommer and Phillip Best read an early version of this review and made helpful suggestions. Discussions of this material with Drs. L. T. Rutledge and Kenneth Casey have been useful.

\section{REFERENCES}

1 ABELES, M., Excitability of EEG 'synchronizing' and 'desynchronizing' neurones in the thalamus and the brain-stem of the cat, $I$. The applicability of strength-duration determinations and conditioning-test techniques, Electroenceph. clin. Neurophysiol., 23 (1967) 16-24.

2 ABELES, M., Excitability of EEG 'synchronizing' and 'desynchronizing' neurones in the thalamus and the brain-stem of the cat, II. Chronaxies and refractoriness, Electroenceph. clin. Neurophysiol., 23 (1967) 25-34.

3 Abzug, C., Maeda, M., Peterson, B. W., and Wilson, V. J., Cervical branching of lumbar vestibulospinal axons, J. Physiol. (Lond.), 243 (1974) 499-522.

4 Ajmone Marson, C., Focal electrical stimulation. In D. P. Purpura, J. K. Penry, D. B. Tower, D. M. Woodbury AND R. D. Walter (Eds.), Experimental Models of Epilepsy, Raven Press, New York, 1972, pp. 96-117.

5 Andersen, P., AND Andersson, S. A., Physiological Basis of the Alpha Rhythm, Appleton-CenturyCrafts, New York, 1968.

6 Armstrong, D. M., HARVey, R J , AND Schild, R. F., The spatial organization of climbing fibre branching in the cat cerebellum, Exp. Brain Res., 18 (1973) 40-58.

7 Baldissera, F., Lundberg, A., ANd Udo, M., Stimulation of pre- and post-synaptic elements in the red nucleus, Exp. Brain Res., 15 (1972) 151-167.

8 Barry, F. E., Walter, M. S., AND Gallistel, C. R., On the optimal pulse duration in electrical stimulation of the brain, Physiol. Behav., 12 (1974) 749-754.

9 BEAN, C. P., Electrical microstimulation of myelinated fibers, Biophys. Soc. Abstr., 13 (1973) $163 \mathrm{a}$. 
10 BeAN, C. P., A Theory of Microstimulation of Myelinated Fibers, Appendix to ref. 3, 1974.

11 BeMENT, S L, AND RANCK, J B., JR., A quantitative study of electrical stimulation of central myelinated fibers with monopolar electrodes, Exp. Neurol., 24 (1969) 147-170.

12 BeMent, S L, AND Ranck, J B., JR., A model for electrical stimulation of central myelinated fibers with monopolar electrodes, Exp. Neurol., 24 (1969) 171-186.

13 BenNetT, M. V. L., Electrical impedance of brain surfaces, Brain Research, 15 (1969) 584-590.

14 Cant, N. W. B., Alterations in Structure and Function of the Visual Systems after Eye Enucleation in Adult Cats, Doctoral Thesis, University of Michigan, 1973.

15 CASEY, K. L., personal communication, 1971.

16 COLE, D. S., AND BAKER, R. F., Transverse impedance of the squid giant axon during current flow, J. gen. Physiol., 24 (1971) 771-778.

17 COLE, K. S., AND BAKER, R. F., Longitudinal impedance of the squid giant axon, J. gen. Physiol. 24 (1941) 771-788.

18 Deutsch, J. A., Behavioral measurement of the neural refractory period and its application to intracranial self-stimulation, J. comp. physiol. Psychol., 58 (1964) 1-9.

19 Doty, R. W., Rutledge, L. T., JR., And LarSen, R. M., Conditioned reflexes established to electrical stimulation of cat cerebral cortex. J. Neurophysiol., 19 (1956) 401-415.

20 FAtт, P., An analysis of the transverse electrical impedance of striated muscle, Proc. roy. Soc. B, 159 (1964) 606-651.

21 FALK, G., AND FATT, P., Linear electrical properties of striated muscle fibres observed with intracellular electrodes, Proc. roy. Soc. B, 160 (1964) 69-123.

22 Frank, K., AND Fuortes, M. G. F., Stimulation of spinal motoneurones with intracellular electrodes, J. Physiol. (Lond.), 134 (1956) 451-470.

23 Fuller, J. H., Brain stem reticular units: some properties of the course and origin of the ascending trajectory, Brain Research, 83 (1975) 349-367.

24 Gallistel, C. R., Note on temporal summation in the reward system, J. comp. physiol. Psychol., 87 (1974) 870-875.

25 Gorman, A. L. F., Differential patterns of activation of the pyramidal system elicited by surface anodal and cathodal cortical stimulation, J. Neurophysiol., 29 (1966) 547-564.

26 GreEN, J. D., AND ADEY, W. R., Electrophysiological studies of hippocampal connections and excitability, Electroenceph. clin. Neurophysiol., 8 (1956) 245-262.

27 Heinbecker, P., Properties of unmyelinated fibers of nerve, Proc. Soc. exp. Biol. (N.Y.), 26 (1929) $340-351$.

28 Hern, J. E. C., Landgren, S., Phillips, C. G., and Porter, R., Selective excitation of corticofugal neurones by surface stimulation of the baboon's motor cortex, J. Physiol. (Lond.), 161 (1962) 73-99.

29 Horrell, R. I., A behavioral estimate of the neurophysiological strength-duration curve, Behav. Biol., 13 (1975) 511-517.

30 Hunt, C. C., And Kuno, M., Properties of spinal interneurones, J. Physiol. (Lond.), 147 (1959) 346-363.

31 IANSEK, R., AND REDMAN, S. J., An analysis of the cable properties of spinal motoneurones using a brief intracellular current pulse, J. Physiol. (Lond.), 234 (1973) 613-636.

32 Jankowska, E., AND Roberts, W. J., An electrophysiological demonstration of the axonal projections of single spinal interneurones in the cat, J. Physiol. (Lond.), 222 (1972) 597-622.

33 Jankowska, E., AND Smith, D. O., Antidromic activation of Renshaw cells and their axonal projections, Acta physiol. scand., 88 (1973) 198-214.

34 Johansson, G. G., Electrical stimulation of a human ventrolateral-subventrolateral thalamic target area, II. Combination of different durations of single pulses with the peak current just adequate to evoke clinical responses, Acta physiol. scand., 72 (1969) 446-455.

35 Katz, B., AND Miledi, R., Propagation of electrical activity in motor nerve terminals, Proc. roy. Soc. $B, 161$ (1965) 453-482.

36 KLEE, M., Intracellular biopotentials during static extracellular stimulation, Biophys. J., 13 (1973) $822-831$.

37 Klee, M., And Plonsey, R., Extracellular stimulation of a cell having a non-uniform membrane, IEEE. Trans. Biomed. Engng, BME-21 (1974) 452-460.

38 Knighton, R. A., An electrically evoked slow potential of the frog's retina. I. Properties of the response, $J$. Neurophysiol., 38 (1975) 185-197.

39 Koslow, M., BaK, A., AND LI, C. L., C-fiber excitability in the cat, Exp. Neurol., 41 (1973) 745753 
40 Landau, W. M., Bishop, G. H., and Clare, M. H., Site of excitation in stimulation of the motor cortex, J. Neurophysiol., 28 (1965) 1206-1222.

41 Landgren, S., Phillips, C. G., and Porter, R., Cortical fields of origin of the monosynpatic pyramidal pathways to some alpha motoneurones of the baboon's hand and forearm, J. Physiol. (Lond.), 161 (1962) 112-125.

42 Lux, H. D., AND Pollen, D. A., Electrical constants of neurons in the motor cortex of the cat, J. Neurophysiol., 20 (1966) 207-220.

43 Maclean, P. D., AND Ploog, D. W., Cerebral representation of penile erection, J. Neurophysiol., 25 (1962) 29-55.

44 Merrill, E. G., Finding a respiratory function for the medullary respiratory neurons. In R. Bellairs and E. G. Gray (Eds.), Essays on the Nervous System, A Festschrift for Professor J. Z. Young, Clarendon Press, Oxford, 1974, pp. 451-486.

45 Mihailovic, L., and Delgado, J. M. R., Electrical stimulation of monkey brain with various frequencies and pulse durations, J. Neurophysiol., 19 (1956) 21-36.

46 Nelson, P. G., AND LuX, H. D., Some electrical measurements of motoneuron parameters, Biophys. J., 10 (1970) 55-73.

47 Nicholson, P. W., Specific impedance of cerebral white matter, Exp. Neurol., 13 (1965) 386-401.

48 Phillips, C. G., AND Porter, R., Unifocal and bifocal stimulation of the motor cortex, J. Physiol. (Lond.), 162 (1962) 532-538.

49 Porter, R., Focal stimulation of hypoglossal neurones in the cat, J. Physiol. (Lond.), 169 (1963) 630-640.

50 Purpura, D. P., And McMurty, J. G., Intracellular activities and evoked potential changes during polarization of motor cortex, J. Neurophysiol., 28 (1965) 166-185.

51 Ranck, J. B., JR., Specific impedance of rabbit cerebral cortex, Exp. Neurol., 7 (1963) 144-152.

52 RANCK, J. B., JR., Analysis of specific impedance of rabbit cerebral cortex, Exp. Neurol., 7 (1963) 153-174.

53 RANCK, J. B., JR., Macroelectrode responses with stimulation and recording within hippocampus and related structures during different states of consciousness, Exp. Neurol., 23 (1969) 207-213.

54 RaNCK, J. B., JR., AND BeMENT, S. L., The specific impedance of the dorsal columns of cat: an anisotropic medium, Exp. Neurol., 11 (1965) 451-463.

55 RoBerts, W. J., AND SMITH, D. O., Analysis of threshold currents during microstimulation of fibres in the spinal cord, Acta. physiol. scand., 89 (1973) 384-394.

56 Rosenthal, F., Extension of single-factor nerve excitation theory to cortical responses, Exp. Neurol., 8 (1963) 125-131.

57 Rosenthal, J., Waller, H. J., and Amassian, V. E., An analysis of the activation of motor cortical neurons by surface stimulation, J. Neurophysiol., 30 (1967) 844-858.

58 Rudin, D. O., ANd Eisenman, G., The action potential of spinal axons in vitro, J. gen. Physiol., 37 (1954) 505-538.

59 Rushton, W. A. H., Effect upon the threshold for nervous excitation of the length of nerve exposed and the angle between current and nerve, J. Physiol. (Lond.), 63 (1927) 357-377.

60 Schaefer, J., Elektrophysiologic 1, Wien Franz Deutticke, Germany, 1940, (J. W. Edwards, Ann Arbor, Mich. 1944).

61 Schlue, W. R., Richter, D. W., Mauritz, K-H., and Nacimiento, A. C., Responses of cat spinal motoneuron somata and axons to linearly rising currents, $J$. Neurophysiol., 37 (1974) 303309.

62 Spehlmann, R., AND KAPP, H., Direct extracellular polarization of cortical neurons with multi barreled microelectrodes, Arch. ital. Biol., 102 (1964) 74-94.

63 Stark, P., Fazio, G., And Boyd, E. S., Monopolar and bipolar stimulation of the brain, Amer. J. Physioi., 203 (1962) 371-373.

64 Stoney, S. D., JR., Thompson, W. D., And Asanuma, H., Excitation of pyramidal tract cells by intracortical microstimulation: effective extent of stimulation current, J. Neurophysiol., 31 (1968) $659-669$.

65 Strumwasser, F., AND Rosenthal, S., Prolonged and patterned direct extracellular stimulation of single neurons, Amer. J. Physiol., 198 (1960) 405-413.

66 Szabo, I., Lenard, L., AND Kosaras, B., Drive decay theory of self-stimulation : refractory periods and axon diameters in hypothalamic reward loci, Physiol. Behav., 12 (1974) 329-343.

67 Szabo, I., And Milner, P. M., Self-stimulation in rats: tip alignment influences the effectiveness of bipolar electrodes, Brain Research, 48 (1972) 243-250. 
68 Szabo, I., AND Milner, P. M., Electrode tip alignment and self-stimulation: influence of anodal hyperpolarization, Physiol. Behav., 11 (1973) 581-583.

69 SZABO, I., AND MILner, P. M., Intracranial self-stimulation in the rat: cable properties of the depolarized membrane, Acta physiol. Acad. Sci. hung., 43 (1973) 65-70.

70 Szabo, I., NAD, E., AND AzABo, C., Pole reversals and hypothalamic self-stimulation: ascending spread of rewarding excitation, Physiol. Behav., 9 (1972) 147-150.

71 Ushiyama, J., KoIzumi, K., and Brooks, C. MCC., Accommodative reactions of neuronal elements in the spinal cord, J. Neurophysiol., 29 (1966) 1028-1045.

72 VALENSTEIN, E. S., AND BEER, B., Unipolar and bipolar electrodes in self-stimulation experiments, Amer. J. Physiol., 201 (1961) 1181-1186.

73 WETZEL, M. C., The identification of self-stimulation elements for adjacent electrodes in the cat, Physiol. Behav., 5 (1970) 899-905.

74 Wilkus, R. J., AND Peiss, C. N., Stimulation parameters for cardiovascular responses from medulla and hypothalamus, Amer. J. Physiol., 205 (1963) 601-605.

75 WISE, R. A., Spread of current from monopolar stimulation of the lateral hypothalamus, Amer. J. Physiol., 223 (1972) 545-548 